\title{
Is OHIP-EDENT similar to GOHAI when Measuring Ohrqol in Partial and Complete Denture Wearers?
}

Mesko ME, Patias R and Pereira-Cenci $\mathbf{T}^{*}$

Graduate Program in Dentistry, Federal University of Pelotas, Pelotas, RS, Brazil

\begin{abstract}
Currently there is no consensus about which is the shortest but still suitable questionnaire for Oral Health Related Quality of Life (OHRQoL) assessment indenture wearers. The aim of this study was to test OHIP-EDENT and GOHAI in a sample of denture wearers. Type of denture (complete or partial), age and location (upper or lower jaws) were compared. The results showed that OHIP-EDENT was more sensible than GOHAI, except for Kennedy Class I and II partial dentures. Patients with lower complete dentures had higher OHRQoL impairment using OHIP-EDENT. GOHAI showed underestimated OHRQoL values for individuals over 60 years old.
\end{abstract}

\section{Keywords: OHIP-EDENT; Denture wearers; Oral health}

\section{Introduction}

Oral cavity, functional, psychosocial aspects and the person's wellbeing are considered for oral health definition [1]. The theoretical model of health and patient's self-perception is the base of several questionnaires created to evaluate and to show how much a condition or a treatment affects individual's OHRQoL [2-4]. Rehabilitation of edentulism tends to improve OHRQoL $[5,6]$ but some individuals may still have some impact on it due to misfits, adaptation phase or because individual lack of acceptance of their dentures [7,8]. No consensus exist when edentulous individuals, complete or partial denture wearers are focused in the research [7,9-16]. Literature shows problems with questionnaire's translation, validation, sensitivity and responsiveness [15,17-19]. It also depends on the method of making the questions [20]. An "as short as possible" easy to apply questionnaire should reduce time and costs [2] without losing properties [21]. Therefore, questionnaire's choice is an important issue.

The Geriatric Oral Health Assessment Index (GOHAI) [2] has 12 questions in three subscales: (1) physical function; (2) psychosocial function and (3) pain or discomfort. It is recommended for clinical and epidemiological surveys for assessing oral health with the elderly [22]. Some authors suggest modifications aiming to improve GOHAI's assessment quality [23]. The Oral Health Imp act Profile for Edentulous (OHIP-EDENT) [21] is an OHIP-49's adapted version retaining the most significant questions from each original subscale because this is considered too long for being used in epidemiological studies [23]. OHIP-EDENT's subscales are functional limitation, physical pain, psychological discomfort, physical disability, psychological disability, social disability and handicap. It is indicated to use for OHRQoL evaluation with elderly or after replacing missing teeth [24] but some authors claim for missing properties in post-treatment evaluations [21]. The criteria for choosing the questionnaire for partial and complete edentulous patients still remains because literature compares GOHAI and OHIP-EDENT for complete denture (CD) wearers [16] but does not compare OHRQoL of removable partial dentures (RPD) wearers with different Kennedy Classes [25]. Despite the little difference on these questionnaires' size, the advantages of using one or another are not clear. Thus, the aim of this study was to test if GOHAI and OHIPEDENT would result in comparable OHRQoL outcomes when applied to partial and complete denture wearers, irrespective of age, type of denture or adjustment of the questionnaire

\section{Methodology}

The study was approved by the Local Research and Ethics
Committee (protocol 217/2011). The inclusion criterion was that the patient had been rehabilitated with a partial or complete removable denture. A list including all patients with partial or complete denture from one month (for the adaptation period) up to 2.5 years of use $[6,17,26]$ was searched in the Dental School. In this list, 200 patients could be retrieved and contacted by telephone but only 148 individuals were found. Regarding the sample, we have invited all patients that were treated at the University; we invited all for a recall aiming to standardize some bias factors. In addition, a sample size calculation was not possible because it was a retrospective study; all the patients treated during two years were invited to come to the University for a Recall Appointment. Patients were excluded for the following reasons: denture-wearing time higher than three years missed the survey appointment, refusal, being in ongoing prosthodontics treatment and never used or lost the denture. Eighty-two patients were examined, but 8 were excluded because these patients were wearing the prostheses for esthetical purposes, but not to eat. The final sample had 74 individuals, most were women under 60 years old and living in the urban area. Their mean age was $58.6( \pm 11.3)$ years old. Questionnaires were applied in a face-to-face interview and the reference period was the last three months. The answers possibilities were 'never', 'seldom', 'sometimes', 'often', and 'always' and scored as 0 , $1,2,3$ or 4 , respectively.

To investigate the influence of the type of prosthesis on OHRQoL, the analysis was divided by dental arches and the sample was therefore considered 120, not 74. Reversal was done for the third and fifth questions as well in the answer of the seventh GOHAI question, according to the validated version of GOHAI used in our study. OHIP-EDENT and GOHAI scores had a direct comparison. An adjustment was done attributing different weights to the GOHAI scores, multiplying it by 1.5833 and generating the GOHAI-adjusted group (GOHAI-adj), considering the difference of number of questions between questionnaires. The calculation of weight was done in mathematical basis because as GOHAI has 12 questions and OHIP-EDENT has 19 it is not possible to compare

*Corresponding author: Tatiana Pereira-Cenci, Graduate Program in Dentistry, Federal University of Pelotas, Pelotas, RS, Brazil, E-mail: tatiana.cenci@ufpel.tche.br

Received August 20, 2013; Accepted October 05, 2013; Published October 08 2013

Citation: Mesko ME, Patias R, Pereira-Cenci T (2013) Is OHIP-EDENT similar to GOHAl when Measuring Ohrqol in Partial and Complete Denture Wearers? Dentistry 3: 160. doi:10.4172/2161-1122.1000160

Copyright: (c) 2013 Mesko ME, et al. This is an open-access article distributed under the terms of the Creative Commons Attribution License, which permits unrestricted use, distribution, and reproduction in any medium, provided the original author and source are credited. 
scores directly with different number of questions. Dividing 19/17 will result in 1.5833; the value took as the weight.

Each arch was considered for comparison according to the type of denture worn: complete denture (CD); Kennedy Class I-II removable partial denture (RPD I-II); and Kennedy Class III-IV removable partial denture (RPD III-IV).The sample was divided in elderly (above 60 years old) or non-elderly (below or equal to 60 years old). Data collection, measurements and comparisons among questionnaires included Brazilian Portuguese versions. The analysis considered type of denture, dental arch location and age. Statistical analyses were done using SigmaStat3.5 (Dundas Softwares Ltd., Erkrath, Germany) with significance level fixed at 5\%. Data from the two questionnaires were analysed using t-test or Mann-Whitney Rank Sum statistical tests (for those that could not be transformed). For questionnaires subscale's comparisons, ANOVA on Ranks were employed.

\section{Results}

Seventy nine per cent of the sample used prosthesis for less than one year. For the questionnaires, considering the worst score for question in the whole sample of 74 patients (Table 1), the impairment of OHQoL happened 'never' and 'seldom' with $70.8 \%$ of them using the OHIPEDENT and $77.6 \%$ with the GOHAI. Impairment happened 'sometimes' in $12.5 \%$ and $12.3 \%$ with the OHIP-EDENT and GOHAI respectively. The answers 'often' represented $4 \%$ with OHIP-EDENT and 3.1\% with the GOHAI. The answers 'always' were $12.7 \%$ with OHIP-EDENT and $7 \%$ with GOHAI. Average and median scores from the comparison between OHIP-EDENT and GOHAI considering the type of prosthesis are showed in Table 2. Significant differences appeared between OHIPEDENT and GOHAI scores when raw or adjusted GOHAI values were used. For RPD I-II there were no differences after adjustment.

No differences were found between OHIP-EDENT and GOHAI scores for complete dentures in maxilla (CDmax), (Table 3) even after adjustment. Impairment was significantly higher for $\mathrm{CDm}$ and ( $\mathrm{p}=0.010$ and 0.038 , for OHIP-EDENT and GOHAI, respectively) comparing to CDmax but it did not occur comparing upper vs. lower arch RPD scores. Table 4 shows scores according to the age. Mean

\begin{tabular}{|c|c|c|c|c|c|c|c|c|c|c|c|c|c|c|c|c|c|c|c|c|}
\hline \multicolumn{21}{|c|}{ OHIP-EDENT } \\
\hline \multicolumn{3}{|c|}{ Functionallimitation } & \multicolumn{4}{|c|}{ Physical pain } & \multicolumn{2}{|c|}{$\begin{array}{l}\text { Psychological } \\
\text { discomfort }\end{array}$} & \multicolumn{3}{|c|}{$\begin{array}{l}\text { Physical dis- } \\
\text { ability }\end{array}$} & \multicolumn{2}{|c|}{$\begin{array}{l}\text { Psychological dis- } \\
\text { ability }\end{array}$} & \multicolumn{3}{|c|}{ Social disability } & \multicolumn{3}{|c|}{ Handicap } & \\
\hline 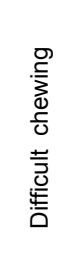 & 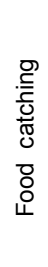 & 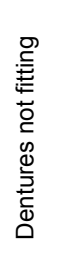 & 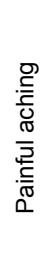 & 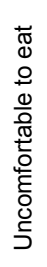 & $\begin{array}{l}\infty \\
0 \\
0 \\
\infty \\
0 \\
0\end{array}$ & 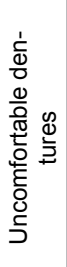 & 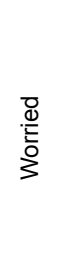 & $\begin{array}{l}0 \\
0 \\
.0 \\
0 \\
0 \\
0 \\
0 \\
\frac{1}{D} \\
\infty\end{array}$ & 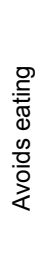 & 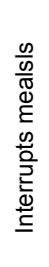 & $\begin{array}{l}\frac{1}{\pi} \\
\Phi \\
0 \\
\stackrel{0}{0} \\
\frac{1}{0} \\
\stackrel{0}{0} \\
\stackrel{5}{D}\end{array}$ & $\begin{array}{l}\stackrel{\varpi}{\Phi} \\
\mathscr{N} \\
\stackrel{D}{\supset}\end{array}$ & 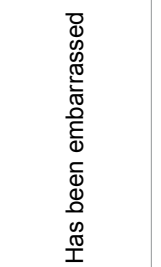 & 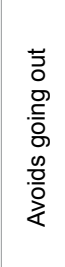 & 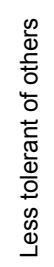 & 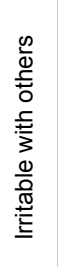 & 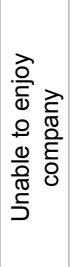 & 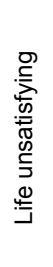 & 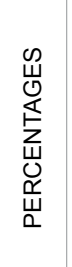 & \\
\hline 31 & 16 & 31 & 51 & 39 & 51 & 39 & 46 & 61 & 45 & 58 & 53 & 59 & 68 & 70 & 73 & 71 & 67 & 66 & 70.8 & Never and seldom \\
\hline 19 & 14 & 15 & 8 & 12 & 10 & 10 & 15 & 9 & 16 & 4 & 11 & 12 & 5 & 3 & 0 & 2 & 6 & 5 & 12.5 & Sometimes \\
\hline 3 & 5 & 8 & 6 & 8 & 4 & 6 & 3 & 0 & 3 & 3 & 4 & 1 & 0 & 0 & 1 & 1 & 0 & 0 & 4.0 & Often \\
\hline 21 & 39 & 20 & 9 & 15 & 9 & 19 & 10 & 4 & 10 & 9 & 6 & 2 & 1 & 1 & 0 & 0 & 1 & 3 & 12.7 & Always \\
\hline \multicolumn{21}{|c|}{ GOHAI } \\
\hline \multicolumn{4}{|c|}{ Physical function } & \multicolumn{4}{|c|}{ Psychosocial function } & \multicolumn{5}{|c|}{ Pain or discomfort } & & & & & & & & \\
\hline 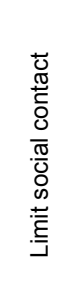 & 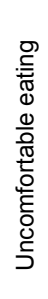 & 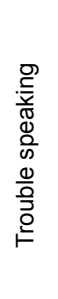 & 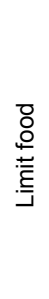 & 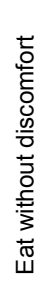 & 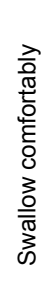 & 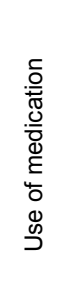 & 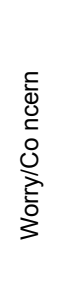 & 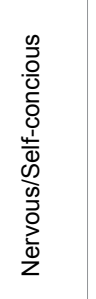 & 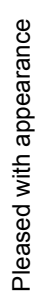 & 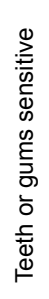 & 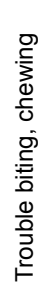 & 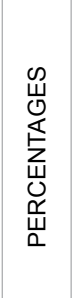 & & & & & & & & \\
\hline 57 & 37 & 67 & 51 & 49 & 69 & 60 & 65 & 57 & 60 & 66 & 51 & 77.6 & $\begin{array}{l}\text { Never and } \\
\text { seldom }\end{array}$ & & & & & & & \\
\hline 9 & 22 & 6 & 13 & 11 & 2 & 2 & 6 & 11 & 7 & 6 & 14 & 12.3 & Someti mes & & & & & & & \\
\hline 3 & 5 & 1 & 1 & 6 & 1 & 3 & 1 & 1 & 3 & 0 & 3 & 3.1 & Often & & & & & & & \\
\hline 5 & 10 & 0 & 9 & 8 & 2 & 9 & 2 & 5 & 4 & 2 & 6 & 7.0 & Always & & & & & & & \\
\hline
\end{tabular}

Table 1: OHRQoL frequency and percentages for the questionnaires tested.

\begin{tabular}{|c|c|c|c|c|c|}
\hline & OHIP-E & GOHAI & GOHAl-adj & $\mathbf{n}$ & $\mathrm{p}^{*}$ \\
\hline$C D$ & $10.8 \pm 13.3 ; 5.5(2.0-12.0)$ & $5.2 \pm 8.5 ; 2.0(0.0-6.0)$ & $8.2 \pm 13.4 ; 3.2(0.0-9.5)$ & 46 & $\begin{array}{l}0.003 \\
0.045\end{array}$ \\
\hline $\begin{array}{c}\text { RPD } \\
\text { I-II }\end{array}$ & $15.1 \pm 12.6 ; 13.0(4.0-20.0)$ & $7.3 \pm 7.5 ; 6.0(0.0-11.8)$ & $11.6 \pm 11.9 ; 9.5(0.0-18.4)$ & 43 & $\begin{array}{c}0.001 \\
0.083^{\Omega}\end{array}$ \\
\hline $\begin{array}{l}\text { RPD } \\
\text { III-IV }\end{array}$ & $13.8 \pm 10.9 ; 10.0(6.3-18.3)$ & $6.8 \pm 7.6 ; 4.0(0.5-11.6)$ & $10.7 \pm 12.1 ; 6.3(0.8-18.6)$ & 31 & $\begin{array}{c}<0.001 \\
0.048\end{array}$ \\
\hline
\end{tabular}

Values are average \pm SD and median (confidence interval $-\mathrm{Cl}$ ); number of patients $(\mathrm{n})$. $¥ \mathrm{p}$ values are the comparison of OHIP-E vs. GOHAl and OHIP-E vs. GOHAl-adj, respectively. $\Omega$ not statistically significant differences. 
Citation: Mesko ME, Patias R, Pereira-Cenci T (2013) Is OHIP-EDENT similar to GOHAl when Measuring Ohrqol in Partial and Complete Denture Wearers? Dentistry 3: 160. doi:10.4172/2161-1122.1000160

Page 3 of 5

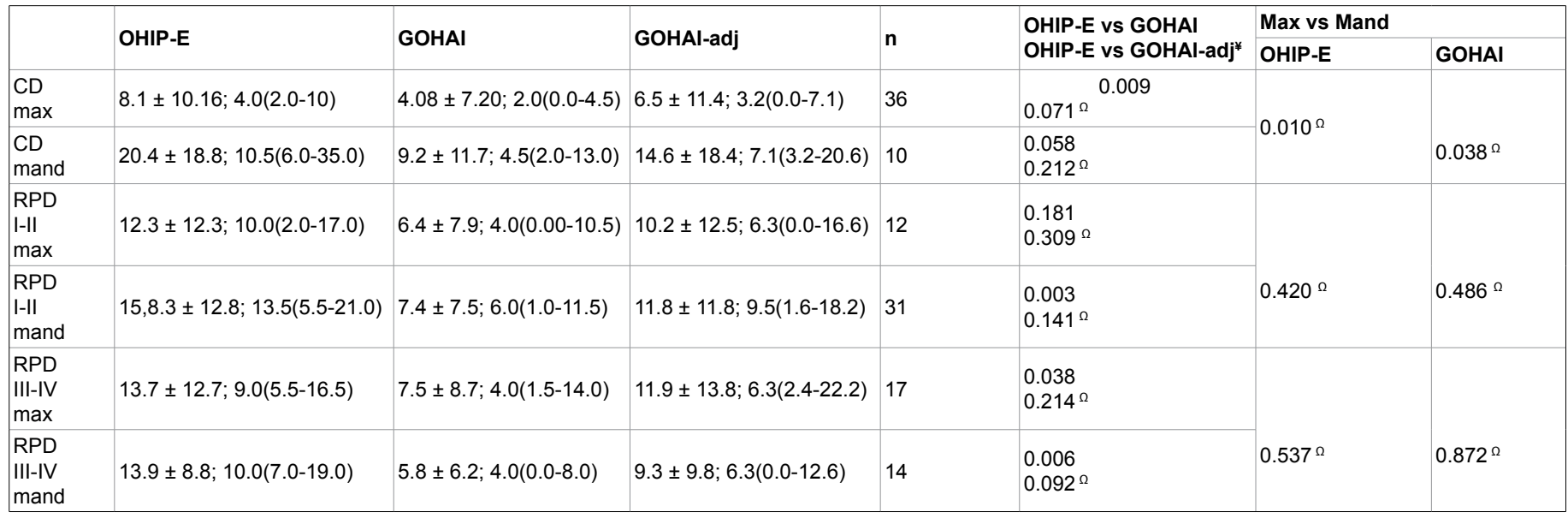

Values are average \pm SD and median (confidence interval - $\mathrm{CI}$ ); $\mathrm{n}=$ number of patients; $¥ \mathrm{p}$ values for the comparison between OHIP-E vs. GOHAI and OHIP-E vs. GOHAIadj, respectively; $\Omega$ represents not statistically significant differences $\alpha$ p values are the comparison between maxillary vs. mandibular arches for different questionnaires, respectively.

Table 3: OHRQoL values for both questionnaires according to dental arch.

\begin{tabular}{|c|c|c|c|c|c|c|}
\hline & OHIP-E & GOHAI & GOHAI-adj & n & $p^{*}$ & \\
\hline$C D \leq 60$ & $10.8 \pm 16.2 ; \quad 4.0(1.5-10.5)$ & $6.4 \pm 10.9 ; 2.0(0.0-8.0)$ & $10.2 \pm 17.2 ; \quad 3.2(0.0-12.7)$ & 17 & $\begin{array}{l}0.191^{\Omega} \\
0.378^{\Omega}\end{array}$ & \\
\hline$C D>60$ & $10.7 \pm 11.6 ; \quad 8.0(2.0-12.0)$ & $4.5 \pm 6.9 ; \quad 2.0(0.0-5.3)$ & $3.2(0.0-8.3)$ & 29 & 0.004 & 0.045 \\
\hline RPD I-II $\leq 60$ & $13.4 \pm 13.1 ; \quad 8.0(2.5-19.0)$ & $7.5 \pm 7.5 ; 6.0(2.0-11.8)$ & $11.9 \pm 11.9 ; \quad 9.5(3.2-18.6)$ & 19 & $\begin{array}{l}0.167^{\Omega} \\
0.770^{\Omega}\end{array}$ & \\
\hline RPD I-II > 60 & $16.5 \pm 12.2 ; 14.0(9.0-22.5)$ & $7.2 \pm 7.6 ; 4.0(0.0-11.5)$ & $11.3 \pm 12.1 ; \quad 6.3(0.0-18.2)$ & 24 & 0.003 & $0.074^{\Omega}$ \\
\hline RPD III-IV $\leq 60$ & $16.5 \pm 13.5 ; 11.5(7.0-23.5)$ & $9.4 \pm 8.9 ; 7.0(2.0-17.5)$ & $14.8 \pm 14.0 ; 11.1(3.2-27.7)$ & 16 & $\begin{array}{l}0.096^{\Omega} \\
0.509^{\Omega}\end{array}$ & \\
\hline RPD III-IV > 60 & $10.9 \pm 6.6 ; \quad 10.0(6.3-15.8)$ & $4.0 \pm 4.9 ; \quad 4.0(0.0-4.0)$ & $6.3(0.0-6.3)$ & 15 & 0.002 & 0.020 \\
\hline
\end{tabular}

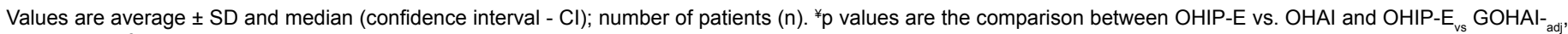
respectively. ${ }^{\Omega}$ represents not statistically significant differences

Table 4: OHRQoL values according for both questionnaires to age.

\begin{tabular}{|c|c|c|c|}
\hline & CD & RPD I-II & RPD III-IV \\
\hline \multicolumn{4}{|l|}{ OHIP-EDENT } \\
\hline Functional limitation & $3.4 \pm 3.3 ; 2.0(0.0-6.0)$ & $3.6 \pm 0.5 ; 6.0(2.3-8.0)$ & $5.7 \pm 2.5 ; 6.0(4.0-8.0)^{\Omega}$ \\
\hline Physical pain & $3.1 \pm 4.9 ; 0.0(0.0-4.0)$ & $4.7 \pm 4.9 ; 4.0(0.0-8.0)$ & $3.5 \pm 3.4 ; 3.0(0.0-5.0)$ \\
\hline Psychological discomfort & $1.3 \pm 1.9 ; 0.0(0.0-2.0)$ & $1.5 \pm 2.4 ; 0.0(0.0-2.0)$ & $1.3 \pm 1.6 ; 0.0(0.0-2.0)$ \\
\hline Physical disability & $2.0 \pm 3.5 ; 0.0(0.0-2.0)$ & $2.2 \pm 3.2 ; 0.0(0.0-3.8)$ & $1.9 \pm 2.9 ; 0.0(0.0-2.0)$ \\
\hline Psychological disability & $0.3 \pm 0.8 ; 0.0(0.0-0.0)$ & $0.6 \pm 1.2 ; 0.0(0.0-0.0)$ & $0.7 \pm 1.6 ; 0.0(0.0-0.0)$ \\
\hline Social disability & $0.2 \pm 1.0 ; 0.0(0.0-0.0)$ & $0.1 \pm 0.4 ; 0.0(0.0-0.0)$ & $0.2 \pm 0.8 ; 0.0(0.0-0.0)$ \\
\hline Handicap & $0.4 \pm 1.4 ; 0.0(0.0-0.0)$ & $0.3 \pm 0.9 ; 0.0(0.0-0.0)$ & $0.5 \pm 1.4 ; 0.0(0.0-0.0)$ \\
\hline \multicolumn{4}{|l|}{ GOHAI } \\
\hline Physical function & $2.2 \pm 3.5 ; 0.0(0.0-2.0)$ & $3.3( \pm 3.6) ; 2.0(0.0-6.0)$ & $2.0 \pm 2.7 ; 2.0(0.0-2.0)$ \\
\hline Psychosocial function & $1.9 \pm 3.6 ; 0.0(0.0-3.0)$ & $2.6( \pm 3.1) ; 2.0(0.0-4.8)$ & $2.9 \pm 3.4 ; 2.0(0.0-5.5)$ \\
\hline Pain or discomfort & $1.1 \pm 2.2 ; 0.0(0.0-2.0)$ & $1.4( \pm 1.9) ; 0.0(0.0-2.0)$ & $1.9 \pm 3.4 ; 0.0(0.0-2.0)$ \\
\hline \multicolumn{4}{|l|}{ GOHAl-adj } \\
\hline Physical function & $3.5 \pm 5.6 ; 0.0(0.0-3.2)$ & $5.2 \pm 5.8 ; 3.2(0.0-9.5)$ & $3.0 \pm 4.3 ; 0.0(0.0-3.2)$ \\
\hline Psychosocial function & $3.0 \pm 5.7 ; 0.0(0.0-4.8)$ & $4.2 \pm 4.9 ; 3.2(0.0-7.5)$ & $4.5 \pm 5.4 ; 3.2(0.0-8.7)$ \\
\hline Pain or discomfort & $5.8 \pm 10.6 ; 0.0(0.0-8.2)$ & $2.3 \pm 2.9 ; 0.0(0.0-3.2)$ & $3.1 \pm 5.5 ; 0.0(0.0-3.2)$ \\
\hline
\end{tabular}

Values are average $\pm \mathrm{SD}$ and median (confidence interval $-\mathrm{CI}$ ); ANOVA on RANKS comparison among different prostheses by subscale for OHIP-E and GOHAI; represents statistically significant differences among $C D$ and the other types of RPD.

Table 5: Subscale values according to different questionnaires.

values were 61.2 for CD; 60.4 for RPD I-II and 53.8 for RPD III-IV. For non-elderly no differences between raw or adjusted scores were found. For the elderly, there were differences between OHIP-EDENT and GOHAI for all types of prosthesis. After the adjustment, differences appeared between CD and RPD III-V $(p=0.020)$. Descriptive values for subscales are shown in Table 5. Functional limitation showed difference in different kinds of prosthesis. Differences occurred between RPD I-II and RPD III-IV groups, with mean values of $3.6 \pm 0.5$ and $5.7 \pm 2.5$, respectively $(\mathrm{p}<0.001)$. Food catching (Table 6$)$ was the only item to show differences for the different prostheses, with RPD I-II and RPD III-IV different from CD $(\mathrm{p}<0.001)$. 


\begin{tabular}{|c|c|c|c|}
\hline & CD & RPD I-II & RPD III-IV \\
\hline Difficulty chewing & $0.0(0.0-2.0)$ & $2.0(0.0-4.0)$ & $0.0(0.0-2.0)$ \\
\hline Food catching & $0.0(0.0-2.0)$ & $4.0(2.0-4.0)$ & $4.0(2.0-4.0)^{\Omega}$ \\
\hline $\begin{array}{c}\text { Dentures not } \\
\text { fitting }\end{array}$ & $0.0(0.0-3.0)$ & $0.0(0.0-3.0)$ & $0.0(0.0-4.0)$ \\
\hline
\end{tabular}

Values are median and confidence interval (ANOVA on Ranks among different prostheses); $\Omega$ represents statistically significant differences among $C D$ and the other types of RPD.

Table 6: Comparison for functional limitation on OHIP-EDENT subscale items.

\section{Discussion}

Our study methodology corroborates with the statement that OHIPEDENT does not cause the called 'floor effect', which is a tendency of the GOHAI or other short questionnaires [21]. The difference in percentage for the OHIP-EDENT in the frequency of 'never/almost never' comparing to the GOHAI was almost the same difference in the frequency of the answers 'always' between these questionnaires, thus there were differences in frequency and a tendency of 'floor effect' for GOHAI. The analysis considered the location of the denture mainly because almost all patients replied back with "Which denture are you talking about, the upper or the lower? thus, patients had different answers for each one of his/her arch. Patients frequently reported that in maxilla everything was all right but the problem for eating, for example, was due to the lower prosthesis. The difficulty in wearing for eating or even because of food retention impacted the OHRQoL occurred in many individuals of the sample. The analysis considering one arch was also performed, but the differences did not appear among the questionnaires; when considering both separately, these differences were remarkable.

Different original or modified questionnaires may be used in the same study for OHRQoL assessment [16,19,23,27,28]. OHIP-EDENT and GOHAI have quite similar domains but they are not equal [27]. The balance of the weight of each domain in GOHAI could be a feasible solution for comparison. Our study was the first to adjust weights to compare OHIP-EDENT and GOHAI scores. Statistical analysis did not show differences comparing the OHIP-EDENT and GOHAI-adj values considering the worst answer with 74 individuals. Most studies usually use the worst score but did not discriminate denture location but patients often answer questionnaires saying that only one of the dentures was causing impact. Moreover, different arch's location can present different retention, stability, acceptance and adaptation degrees.

Literature shows similar impairment levels comparing OHRQoL with CD and RPD wearers [29] but other studies show the opposite $[11,16]$. Our results presented differences between CD and RPD I-II. We suppose that the RPD I-II group showed different response levels because functional limitation is well assessed with the GOHAI' $[19,27]$. Comparison between maxillary vs. mandibular arches was made. Raw data from OHIP-EDENT vs. GOHAI showed that the groups CDmax, RPD I-IIm and, RPD III-IV max and RPD III-IVm and did not present significant differences after adjustments. Impairment in the lower arch was higher than in the upper arch solely for CD wearers, irrespective of the questionnaire used. Mandibular stability and retention of conventional CD were often worse than in the maxilla [6], corroborating our findings. Data in literature assessing different location of CD and RPD are scarce or lacking. Irrespective on the type of denture tested, in individuals below 60 years old, impairment differences were not present. For the elderly patients, except in the RPD I-II group, the differences between OHIP-EDENT and GOHAI and OHIP-EDENT vs. GOHAI-adj found in our study corroborated with a study that showed that GOHAI scores tends to decrease as age increases [16].
Functional limitation was the only subscale to show differences among all groups. Discriminating the subscale items "difficulty of chewing" and "fitting" of RPD was not impacting but "food catching" was the most impacting item that differs RPD from CD wearers, which is in agreement with another study [29]. Data from OHIPEDENT and GOHAI could be different when assessing OHRQoL in elderly populations, as our analysis has shown. Moreover, the level of impairment in the lower arch, in our sample, was higher than in the upper arch for complete denture wearers irrespective of the questionnaire used. One limitation of our study was the fact that we have had very few male patients over 60 years old or patients who lived in the countryside. Conclusions cannot be drawn for this specific population, while they remain to be studied.

\section{Conclusion}

OHRQoL assessment with GOHAI and OHIP-EDENT were similar. Little differences occurred between the different domains, as functional domains produced different impairment in complete denture wearers in our study. GOHAI should be used with caution when assessing elderly individuals, as it resulted in a tendency of 'floor effect' for the OHRQoL results, while OHIP-EDENT did not.

\section{References}

1. Sischo L, Broder HL (2011) Oral health-related quality of life: what, why, how, and future implications. J Dent Res 90: 1264-1270.

2. Atchison KA, Dolan TA (1990) Development of the Geriatric Oral Health Assessment Index. J Dent Educ 54: 680-687.

3. Locker D (1988) Measuring oral health: a conceptual framework. Community Dent Health 5: 3-18.

4. Souza RF de, Leles CR, Guyatt GH, Pontes CB, Della Vecchia MP, et al. (2010) Exploratory factor analysis of the Brazilian OHIP for edentulous subjects. J Oral Rehabil 37: 202-208

5. Crocombe LA, Mejia GC, Koster CR, Slade GD (2009) Comparison of adult ora health in Australia, the USA, Germany and the UK. Aust Dent J 54: 147-153.

6. Veyrune JL, Tubert-Jeannin S, Dutheil C, Riordan PJ (2005) Impact of new prostheses on the oral health related quality of life of edentulous patients. Gerodontology 22: 3-9.

7. Shigli K, Hebbal M (2010) Assessment of changes in oral health-related quality of life among patients with complete denture before and 1 month post-insertion using Geriatric Oral Health Assessment Index. Gerodontology 27: 167-173.

8. John MT, Koepsell TD, Hujoel P, Miglioretti DL, LeResche L, et al. (2004) Demographic factors, denture status and oral health-related quality of life. Community Dent Oral Epidemiol 32: 125-132.

9. Montero J, López JF, Galindo MP, Vicente P, Bravo M (2009) Impact of prosthodontics status on oral well-being: a cross-sectional cohort study. J Oral Rehabil 36: 592-600.

10. Rodrigues SM, Oliveira AC, Vargas AM, Moreira AN, Ferreira EF (2012) Implications of edentulism on quality of life among elderly. Int J Environ Res Public Health 9: 100-109.

11. Montero J, Bravo M, López-Valverde A (2011) Development of a specific indicator of the well-being of wearers of removable dentures. Community Dent Oral Epidemiol 39: 515-524.

12. John MT, Slade GD, Szentpétery A, Setz JM (2004) Oral health-related quality of life in patients treated with fixed, removable, and complete dentures 1 month and 6 to 12 months after treatment. Int J Prosthodont 17: 503-511.

13. Pace-Balzan A, Butterworth CJ, Dawson LJ, Lowe D, Rogers SN (2008) The further development and validation of the Liverpool Oral Rehabilitation Questionnaire (LORQ) version 3: a cross-sectional survey of patients referred to a dental hospital for removable prostheses replacement. J Prosthet Dent 99: 233-242.

14. Stober T, Danner D, Lehmann F, Séché AC, Rammelsberg P, et al. (2012) Association between patient satisfaction with complete dentures and oral health-related quality of life: two-year longitudinal assessment. Clin Ora Investig 16: 313-318. 
Citation: Mesko ME, Patias R, Pereira-Cenci T (2013) Is OHIP-EDENT similar to GOHAl when Measuring Ohrqol in Partial and Complete Denture Wearers? Dentistry 3: 160. doi:10.4172/2161-1122.1000160

15. Pires CP, Ferraz MB, de Abreu MH (2006) Translation into Brazilian Portuguese, cultural adaptation and validation of the oral health impact profile (OHIP-49). Braz Oral Res 20: 263-268.

16. AIBaker AM (2012) The oral health-related quality of life in edentulous patients treated with conventional complete dentures. Gerodontology 30: 61-66.

17. Oliveira BH de, Nadanovsky P (2005) Psychometric properties of the Brazilian version of the Oral Health Impact Profile-short form. Community Dent Oral Epidemiol 33: 307-314.

18. Souza RF de, Patrocínio L, Pero AC, Marra J, Compagnoni MA (2007) Reliability and validation of a Brazilian version of the Oral Health Impact Profile for assessing edentulous subjects. J Oral Rehabil 34: 821-826.

19. Souza RF de, Terada AS, Della Vecchia MP, Regis RR, Zanini AP, et al. (2012) Validation of the Brazilian versions of two inventories for measuring oral healthrelated quality of life of edentulous subjects. Gerodontology 29: 88-95.

20. Sousa PC, Mendes FM, Imparato JC, Ardenghi TM (2009) Differences in responses to the Oral Health Impact Profile (OHIP14) used as a questionnaire or in an interview. Braz Oral Res 23: 358-364.

21. Allen F, Locker D (2002) A modified short version of the oral health impact profile for assessing health-related quality of life in edentulous adults. Int J Prosthod 15: 446-450.

22. Atchison KA (1997) The General Oral Health Assessment Index (GOHAI). Measuring oral health and quality of life. Chapel Hill, University of North Carolina: Dental Ecology.
23. Kshetrimayum N, Reddy CV, Siddhana S, Manjunath M, Rudraswamy S, et al. (2012) Oral health-related quality of life and nutritional status of institutionalized elderly population aged 60years and above in Mysore City, India. Gerodontology 30: 119-125.

24. Slade GD (1997) Derivation and validation of a short-form oral health impact profile. Community Dent Oral Epidemiol 25: 284-290.

25. Miller EL (1970) Systems for classifying partially dentulous arches. J Prosthet Dent 24: 25-40.

26. Inukai M, Baba K, John MT, Igarashi Y (2008) Does removable partial denture quality affect individuals' oral health? J Dent Res 87: 736-739.

27. Locker D, Matear D, Stephens M, Lawrence H, Payne B (2001) Comparison of the GOHAl and OHIP-14 as measures of the oral health-related quality of life of the elderly. Community Dent Oral Epidemiol 29: 373-381.

28. Hassel AJ, Danner D, Schmitt M, Nitschke I, Rammelsberg P, et al. (2011) Oral health-related quality of life is linked with subjective well-being and depression in early old age. Clin Oral Investig 15: 691-697.

29. Bae KH, Kim C, Paik DI, Kim JB (2006) A comparison of oral health related quality of life between complete and partial removable denture-wearing older adults in Korea. J Oral Rehabil 33: 317-322. 